\title{
The Function of Dendritic Spines: Devices Subserving Biochemical Rather Than Electrical Compartmentalization
}

\author{
Christof Koch ${ }^{1}$ and Anthony Zador ${ }^{2}$ \\ 'Computation and Neural Systems Program, California Institute of Technology, Pasadena, California 91125 and \\ ${ }^{2}$ Neuroscience Program, Yale University School of Medicine, New Haven, Connecticut 06510
}

Dendritic spines are tiny, specialized protoplasmic protuberances that cover the surface of many neurons. First described by Ramon y Cajal (1991) in light microscopic studies of Golgistained tissue, they are among the most striking subcellular features of many neurons. Spines serve as the major target for excitatory synaptic input onto principal neurons in the hippocampus, the neocortex, and other brain regions. Their intimate association with synaptic traffic suggests some critical role in synaptic transmission and plasticity. We here review experimental data and theoretical models with respect to the putative role of dendritic spines in the induction and retention of synaptic plasticity.

The ubiquity of spines demands explanation, yet their small size-near the limit of resolution of light microscopy-impedes an experimental frontal assault. Until recently, most theoretical studies focused on the role of the spine neck geometry in regulating the amplitude of the EPSP received at the soma. However, recent experimental evidence suggests that the spine shape may not be able to modulate the "synaptic weight" effectively. Consequently, both theoretical models and calcium-imaging experiments are now focusing on the role of spines in amplifying and isolating calcium signals, particularly those involved in the induction of a calcium-dependent form of long-term synaptic plasticity.

Until recently, physiological hypotheses about the function of the dendritic spines could only be explored indirectly, through analytical and computational studies based on morphological data. Recent technical advances in the direct visualization of calcium dynamics in dendritic structures are now permitting direct tests of some of these theoretical inferences.

Three principal hypotheses have been advanced to explain the function of spines: (1) spines connect axons with dendrites,

\section{[Key words: dendritic spines, voltage attenuation, bio- chemical compartmentalization, calcium dynamics, pyra- midal cells, long-term potentiation]}

Some of the research reported here is supported by the Office of Naval Research, the National Science Foundation, the James S. McDonnell Foundation, and the National Institute of Mental Health Center for cell and molecular signalling. C.K. thanks the Aspen Center of Physics for its hospitality during the preparation of this review, and A.Z. thanks Ed Kairiss for generously making his computer facilities available. We thank Idan Segev and Rodney Douglas for helpful comments.

Correspondence should be addressed to Dr. Christof Koch, Computation and Neural Systems Program, 216-76, Division of Biology, California Institute of Technology, Pasadena, CA 91125.

Copyright (C) 1993 Society for Neuroscience 0270-6474/93/130413-10\$05.00/0
(2) spines shape the membrane potential in response to synaptic input, and (3) spines determine the dynamics of intracellular second messengers such as calcium. In this article we review the current status of each of these proposals with particular emphasis on the putative role of spines in the induction of a cellular model of synaptic plasticity in cortical structures, longterm potentiation (LTP).

It may well be possible that dendritic spines serve some crucial role in normal synaptic transmission (D. Purves, personal communication). However, in this article we focus on their possible role in synaptic plasticity. Furthermore, we will not discuss the electrical behavior of that minority of spines in neocortex that carry both an excitatory and an inhibitory synapse (see Koch and Poggio, 1983a; Qian and Sejnowski, 1989, 1990; Dehay et al., 1991), nor will we consider the role of dendrodendritic synapses, such as those found on the spines of olfactory granule cells (Rall and Shepherd, 1968; Shepherd and Greer, 1989).

\section{The Natural History of Spines}

We first summarize some of the pertinent facts about dendritic spines, with particular emphasis on neocortex and hippocampus, before discussing their functional role.

\section{The distribution of spines}

In neocortex, hippocampus, and olfactory cortex, neurons are classified according to whether their dendrites are studded with spines. Spiny neurons include pyramidal and stellate cells. They account for about three quarters of neurons in the neocortex. Smooth neurons, whose dendrites carry few or no spines, make up the remainder. Smooth neurons include the basket cell, the chandelier or axoaxonic cell, and the double-bouquet cell; they stain for the inhibitory neurotransmitter GABA (Douglas and Martin, 1990). It has not been explained why one class of cortical cells, inhibitory interneurons, should have so few spines, while excitatory cells have so many.

A large, layer $\mathrm{V}$ pyramidal cell in the visual cortex may have as many as 15,000 spines, averaging about two spines per micrometer of dendrite (Larkman, 1991; see also Schüz, 1976), while the reported density for CA1 pyramidal cells varies from about one to five spines per micrometer of dendrite, depending on the staining method used (Harris and Stevens, 1989; Amaral et al., 1990). The record is held by cells in the human cerebellum, where individual Purkinje cells are studded by up to 200,000 spines, each spine carrying a single excitatory synapse from a parallel fiber (Braitenberg and Atwood, 1958). 


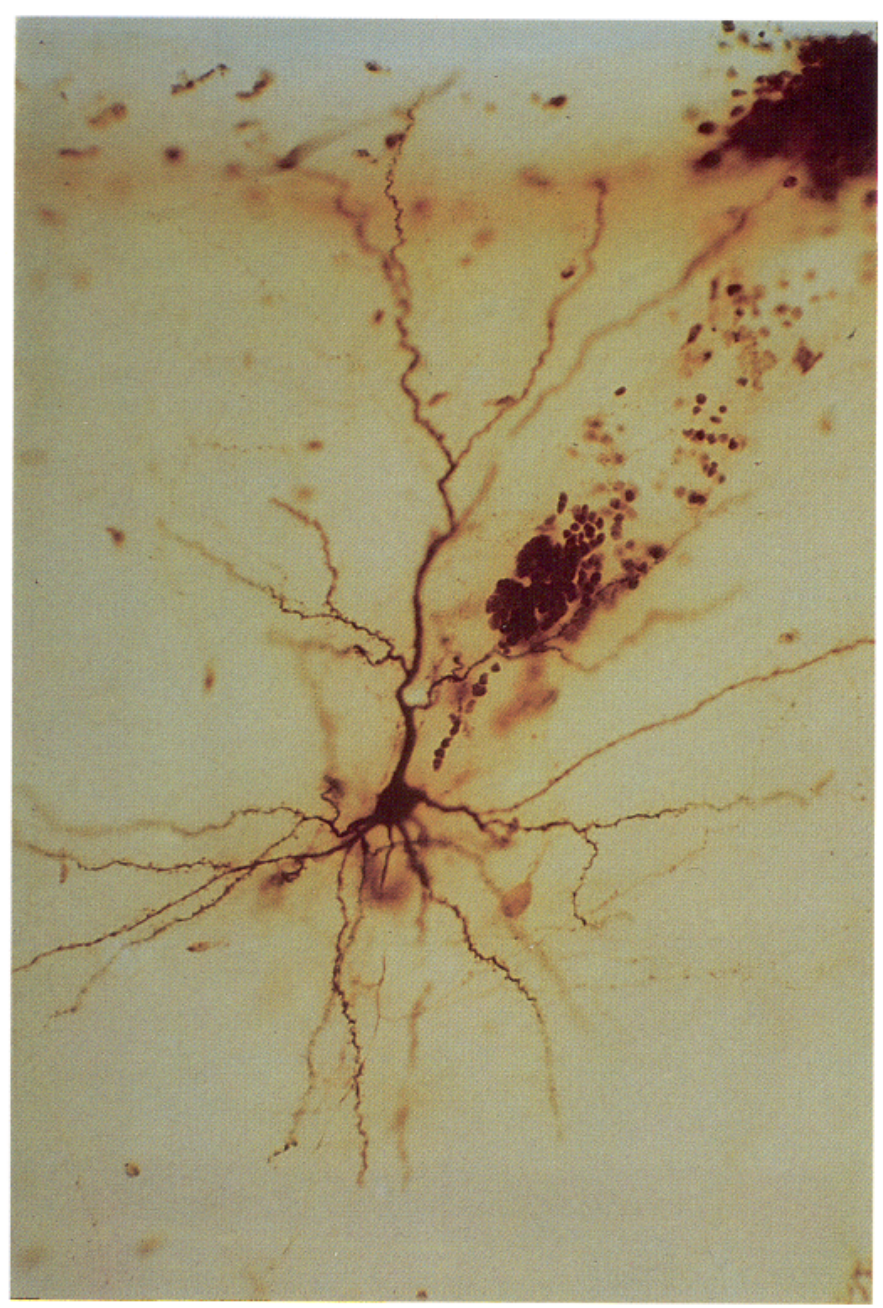

Figure 1. A pyramidal cell in layer 2 of cat visual cortex. The cell was filled intracellularly with HRP. Dendritic spines are seen on the apical and basal dendrites (see Martin and Whitteridge, 1984, their Fig. 7A).

\section{The microanatomy of spines}

Spines are found in a wide variety of shapes (Jones and Powell, 1969; Peters and Kaiserman-Abramof, 1970; see also Figs. 13), ranging from the short and stubby, through the archetypal "mushroom-shaped," to the long and thin. In general, spines can be described as having a "neck" that emerges from the dendrite and ends with a "head." Sometimes multiple spines can branch from a single dendritic protrusion. The exact morphology of spines can only be appreciated by means of threedimensional reconstructions of serial electron micrographic sections, as first reported by Wilson et al. (1983) in the neostriatum and later by Harris and Stevens (1988a,b, 1989) in cerebellum and cortex (see Fig. 3). For CA1 pyramidal cells in the rat hippocampus, Harris and Stevens (1989) found wide variability in the dimensions of spines, with spine necks ranging in length from 0.08 to $1.6 \mu \mathrm{m}(0.45 \pm 0.29 \mu \mathrm{m})$ and in diameter from 0.04 to $0.46 \mu \mathrm{m}(0.15 \pm 0.06 \mu \mathrm{m})$. The total volume of neck plus head was $0.062 \pm 0.08 \mu \mathrm{m}^{3}$. Larger spine heads were associated with larger synapses, as measured by the size of the associated postsynaptic density, and by the number of vesicles in the presynaptic axonal varicosity. These dimensions emphasize that spines bridge the gap between the cellular and the molecular scales. For example, at a resting concentration of 80 nM only about three unbuffered $\mathrm{Ca}^{2+}$ ions are present in the average spine head of volume $0.05 \mu \mathrm{m}^{3}$.

Dendritic spines are characterized by an absence of mitochondria, microtubules, or ribosomes, and by the presence of a specialized form of smooth endoplasmic reticulum termed the "spine apparatus." The membranes making up the spine apparatus are closely apposed to the plasma membrane of the spine neck and appear to sequester calcium (Burgoyne et al., 1983; Fifkova et al., 1983). Although spines lack neurofilaments, spine heads contain a dense network of actin filaments (Fifkova and Delay, 1982). In the neck, actin filaments are oriented lengthwise along the spine apparatus (Fifkova, 1985). A number of proteins known to be involved in actin-mediated activities, including neuronal myosin (Drenckhahn and Kaiser, 1983), fodrin (Carlin et al., 1983), and calmodulin (Caceres et al., 1983), have been found in dendritic spines.

The close association of spines with terminal boutons of axons prompted early speculation that spines might conduct impulses between neurons, although at the time little was known about the basic mechanisms of synaptic transmission. EM studies have since confirmed that spines are indeed the major postsynaptic target of excitatory (asymmetric, type I) synaptic input (Gray, 1959). In cat visual cortex, over $90 \%$ of the afferent geniculate terminals in layer IV are located on spines (White and Rock, 1980; LeVay, 1986; Martin, 1988). This association is limited to excitatory synaptic traffic. Inhibitory (symmetric, type II) synaptic input is observed only at a small fraction (between $5 \%$ and $20 \%$ ) of spines in the neocortex, and always in conjunction with excitatory input (Jones and Powell, 1969; see Fig. $1 C$ in Dehay et al., 1991). In hippocampus, no inhibitory terminals

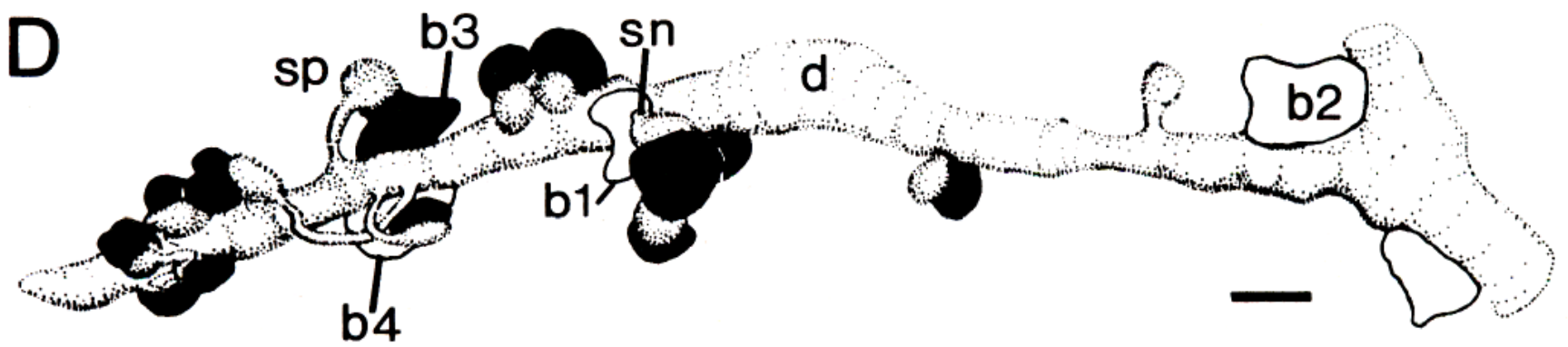

Figure 2. A reconstruction from serial EM sections of a proximal dendrite of an HRP-filled spiny stellate neuron in layer $4 \mathrm{a}$ of cat visual cortex $s p$, spine; $s n$, spine neck; $b 1$, symmetrical synapsing bouton on spine neck; $b 2$, symmetrical synapsing bouton on branch point; $b 3$, asymmetrical synapsing bouton on spine; $b 4$, symmetrical synapsing bouton on dendritic shaft; $d$, dendritic shaft. Scale bar, $1 \mu \mathrm{m}$ (from Anderson et al., in press, with permission). 
are observed on dendritic spines (K. Harris, personal communication).

\section{Changes in spine morphology}

Both the absolute number as well as the shape of spines can change dramatically with a number of external variables. For instance, in the CA1 region of the hippocampus, the dendritic spine density varies by $30 \%$ or more over the $5 \mathrm{~d}$ estrus cycle of the adult female rat, while spines on pyramidal cells in the CA3 region showed little statistical significant variation (Woolley et al., 1990). Other studies have shown that the shape of spines-in particular the length and diameter of the neckchanges during the course of neuronal development (Harris et al., 1989, 1992), and in response to behavioral or environmental cues such as light, social interaction, or exploratory motor activity (Purpura, 1974; Coss and Globus, 1978; Bradley and Horn, 1979; Brandon and Coss, 1982; Rausch and Scheich, 1982). Other studies have found a correlation between changes in spine shape and brief high-frequency electrical stimulation of specific hippocampal pathways sufficient to induce LTP (Van Harrefeld and Fifkova, 1975; Lee et al., 1980; Fifkova et al., 1982; Greenough and Chang, 1985). Some of the reported changes include larger spine heads, changes in the shape of the spine stem, an increased incidence of concave spine heads, and an increase in the number of shaft synapses. It is not known what role-if any-these changes in spine shape play in the increase in synaptic efficacy. Furthermore, the interpretation of the data is itself problematic (Desmond and Levy, 1988).

\section{First Hypothesis: Spines Only Connect}

Spines as connecting tissue

The earliest view of spines focused on an anatomical rather than a physiological role (Ramon y Cajal, 1991). One specific hypothesis was that spines provide sufficient surface area on the dendrite for synapse formation. However, the three-dimensional EM reconstructions by Harris and Stevens (1988a) argue against this view. By graphically removing all spines from their computer reconstructions of spiny dendrites, they estimated that only $29-45 \%$ of the dendritic membrane area of Purkinje cells would have been covered by synapses if all spines were deleted and the associated synapses moved to the dendrites. Applying the same technique to five reconstructed CA1 pyramidal cell dendrites, they found that only about $5-9 \%$ of the remaining dendritic surface area would have been covered by the synapses from the spines. Thus, it does not appear that spines are required for lack of dendritic membrane area. These results do not, however, preclude a role for spines in simplifying the connectivity between axonal and dendritic processes in the three-dimensional neuropil (Swindale, 1981).

\section{Effect of spines on properties of dendrites}

Given the high density of spines per micrometer of dendrites (up to 14 spines/ $\mu \mathrm{m}$ on Purkinje cells; Harris and Stevens, 1988b), a substantial fraction of the total membrane area of many neurons resides in spines. It is therefore important to account for this additional area in the analysis of the passive propagation of electrical signals within the dendritic tree. In particular, from the vantage point of a somatic recording site, both the total capacitance and the electrotonic length of the dendrite increase while the resistance decreases when spines are added to "smooth" membrane. A number of techniques have been devised to simplify the analysis of this effect.

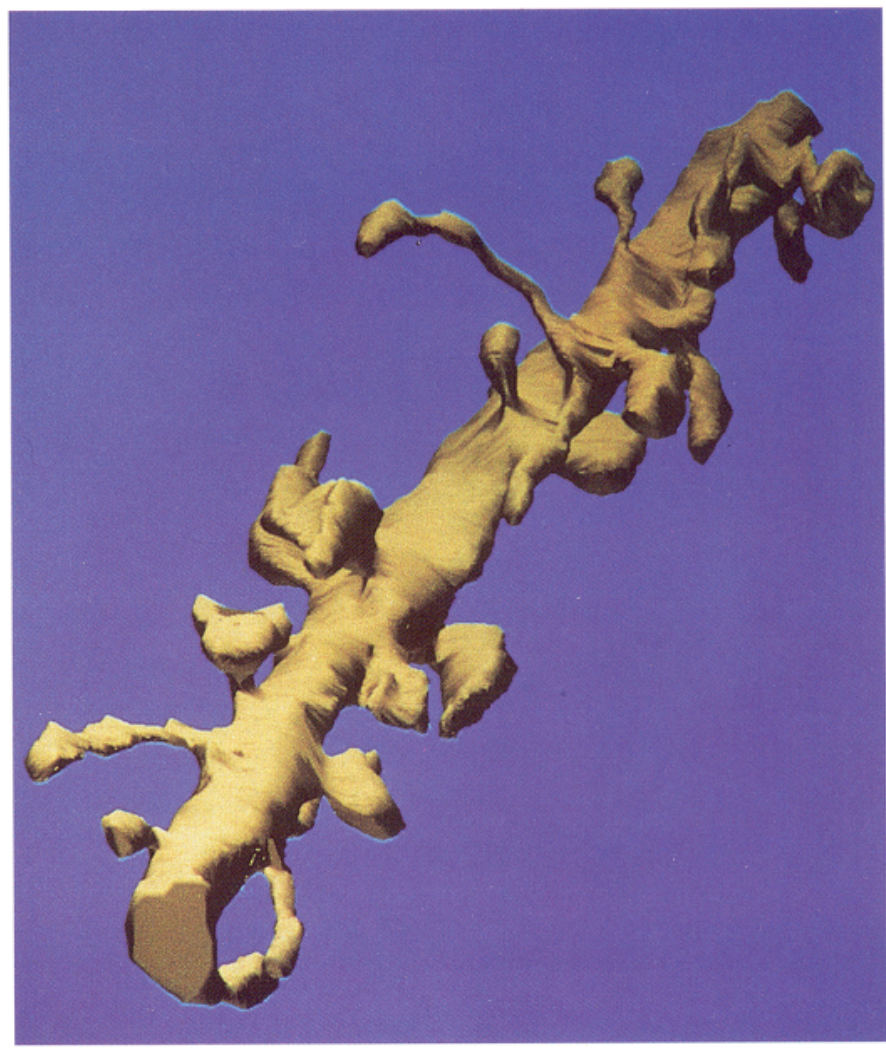

Figure 3. Three-dimensional reconstruction of an $8.5-\mu \mathrm{m}$-long dendrite from a CA1 pyramidal cell of the rat hippocampus. The dendritic diameter ranges from 0.51 to $0.73 \mu \mathrm{m}$. There are about three spines per micrometer. The diversity of spine shapes and dimensions is especially striking (from Harris and Stevens, 1989, with permission).

One method (Stratford et al., 1989) transforms the spiny dendrite into a single "equivalent" (and smooth) cylinder, whose diameter and length are larger than those of the parent dendrite by some appropriate fraction. A second method (Holmes, 1989; Claiborne et al., 1992; Segev et al., 1992) preserves the dimensions of the dendrite but increases the membrane capacitance $C_{m}$ and decreases the membrane resistance $R_{m}$ appropriately. A novel analytical method to incorporate spines into cable theory was developed by Baer and Rinzel (1991). Although the effect that the increased spine membrane area has on the electrical properties of the cell provides no insight into the function of spines, it may ironically be the only one that we can infer with confidence to be important (see also Jaslove, 1992).

\section{Second Hypothesis: Spines Play an Electrical Role}

Chang (1952) was the first to point out that the spine neck might sculpt the electrical signal generated by the synapse: "If the end bulbs of the gemmules [spines] are the receptive apparatus for the presynaptic impulses, the process of postsynaptic excitation initiated there must be greatly attenuated during its passage through the stems of the gemmules which probably offer considerable ohmic resistance because of their extreme slenderness." This observation was extended by Rall (1970; see also Diamond et al., 1970), who proposed that “. .. the spine stem resistance could be an important variable which might be used physiologically to change the relative weights of synaptic inputs from different afferent sources." Bliss and Lomo (1973) invoked this as a possible mechanism for LTP in their original description of that phenomenon. 


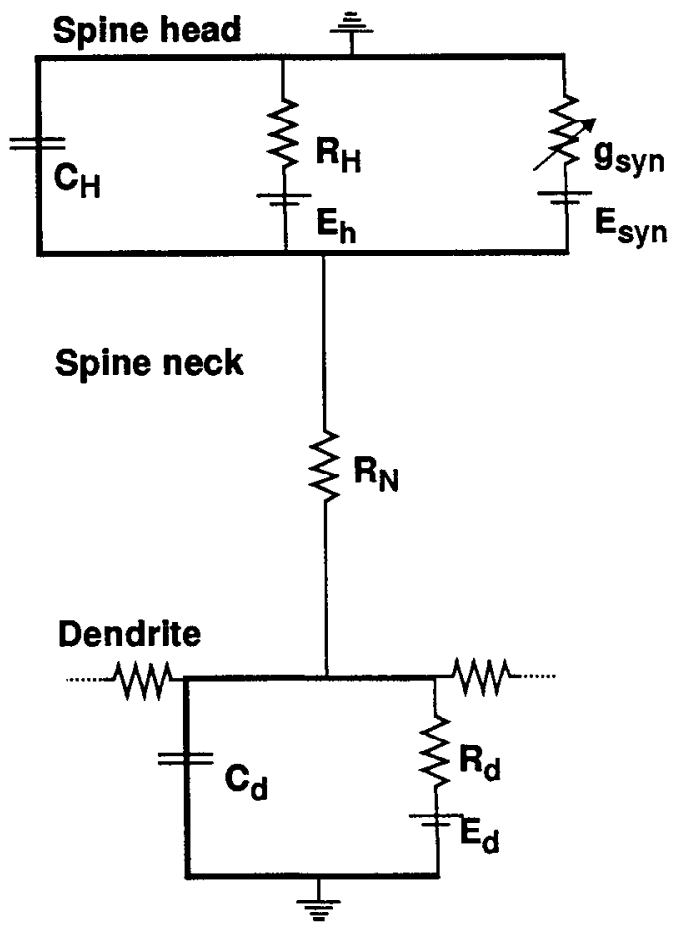

Figure 4. Simplified electrical model of a passive spine. The leak through the spine neck membrane is so small that it has not been included.

This basic idea was analyzed and refined in subsequent years by many authors (Rall and Rinzel, 1971; Rall, 1974, 1978; Jack et al., 1975; Rinzel, 1982; Koch and Poggio, 1983a,b; Turner, 1984; Wilson, 1984; Perkel and Perkel, 1985; Shepherd et al., 1985; Brown et al., 1988b; Segev and Rall, 1988). In a radical extension of this original idea, Crick (1982) advanced the "twitching spine hypothesis"- the notion that spines, using actin-based contractile machinery in the spine neck, could subserve very fast changes (less than a second) in synaptic efficacy, and that this might provide a mechanism for short-term mcmory. Let us review the main argument in the case of a passive, voltage-independent spine membrane.

\section{Passive electrical properties of spines}

Theoretically, spines could attenuate the synaptic signal in two ways. First, they could reduce the current reaching the parent dendrite by allowing current loss through the spine neck membrane. While this is possible in principle, analysis over a wide range of spine geometries and passive membrane parameters suggests that current loss across the spine neck is negligible. The explanation is simply that current loss is proportional to membrane surface area, and the spine neck area is very small (Harris and Stevens, 1989). In the analysis that follows we will show that when a synapse behaves as a current source, the spine neck provides very little electrical isolation between the spine head and the parent dendrite.

However, spines could also attenuate the synaptic signal via a second mechanism. Because the spine has a greater input resistance than the parent dendrite, the same synaptic conductance change produces more depolarization at the spine than at the dendrite. As a consequence, the driving potential at the spine head decreases more than at the parent dendrite, such that a smaller synaptic current is generated at the spine head. Since the depolarization at any remote site is proportional to the injected current, this synaptic saturation increases the effective attenuation between that site and the synapse. If the conductance change is large enough, the driving potential approaches zero and the spine synapse acts as a voltage source (see below).

What biophysical factors determine whether the spine operates in the voltage or current regime? We can quantify this question by analyzing the electrical circuit corresponding to a highly simplified model of a spine attached to a dendrite (Fig. 4; for more details, see Koch and Poggio, 1983a). The steadystate case is particularly simple [the analysis of the transient case is more involved, but the result is essentially the same, because due to the extremely small capacitance $C_{H}$ of the spine head membrane $(<0.01 \mathrm{pF})$, the spine input impedance changes little at high frequencies; Jack et al., 1975; Koch and Poggio, 1983a].

Any current injected into the spine head must flow either out across the spine head resistance $R_{H}$ or in through the spine neck resistance $R_{N}$ and along the dendritic input resistance $R_{d}$. However, given the very small spine membrane area of $\ll 1 \mu \mathrm{m}^{2}$ (Harris and Stevens, 1989), $K_{H}$ is so large $\left(>10^{6} \mathrm{M} \Omega\right.$ ) that it can be assumed to be infinite. The spine input resistance $R_{\text {spine }}$ is therefore simply the sum of the ncck resistancc and the dendritic input resistance just below the spine:

$$
R_{\text {spine }}=R_{N}+R_{d} \text {. }
$$

We can express the current flowing across the synapse at the spine head as

$$
I_{\mathrm{syn}}=g_{\mathrm{syn}}\left(E_{\mathrm{syn}}-V_{s}\right)
$$

where $g_{\text {syn }}$ is the synaptic input conductance at the spine head, $E_{\text {syn }}$ is the synaptic reversal potential, and $V_{s}$ is the amplitude of the EPSP at the spine head (Fig. 4). Applying Ohm's law, we multiply Equation 2 by the input resistance $R_{\text {spine }}$ and solve for $V_{s}$. By a simple algebraic manipulation, we obtain

$$
V_{s}-\frac{g_{\mathrm{syn}} R_{\mathrm{spine}} E_{\mathrm{syn}}}{1+g_{\mathrm{syn}} R_{\mathrm{spine}}}
$$

Similarly, the amplitude $V_{d}$ of the EPSP at the dendrite just below the spine is given by

$$
V_{d}=\frac{g_{\mathrm{syn}} R_{d} E_{\mathrm{syn}}}{1+g_{\mathrm{syn}} R_{\mathrm{spine}}} .
$$

Let us consider these equations in the limits of very small and large synaptic inputs.

If the synaptic input conductance $g_{\text {syn }}$ is small relative to the spine input resistance $R_{\text {spine }}$ (i.e., $g_{\text {syn }} R_{\text {spine }} \ll 1$ ), then the denominator in Equations 3 and 4 is close to unity and the spine and dendritic EPSPs can be expressed as

$$
V_{s} \approx g_{\text {syn }} R_{\text {spine }} E_{\text {syn }}
$$

and

$$
V_{d} \approx g_{\mathrm{syn}} R_{d} E_{\mathrm{syn}}
$$

That is, under these conditions, the action of the synapse can be approximated by a current source of amplitude $g_{\text {syn }} E_{\text {syn }}$. Since the dendritic EPSP depends on $R_{d}$ but not on $R_{\text {spine, }}$ it follows that $V_{d}$ is independent of spine geometry, which affects only $R_{\text {spine }}$. In other words, the synapse can be thought of as injecting the current $g_{\text {syn }} E_{\text {syn }}$ into the spine head; almost none of this current will leak out through the tiny spine neck and head membrane and therefore almost all of the current will reach the dendrite, regardless of the size of the spine neck. However, 
because of the difference in input resistance between the spine head and the dendrite, the dendritic EPSP will be attenuated with respect to the spine FPSP by a factor of $V_{d} / V_{s}=R_{d} /\left(R_{d}+\right.$ $\left.R_{N}\right)$.

If, on the other hand, $g_{\mathrm{syn}}$ is large relative to $R_{\mathrm{spine}}$ (i.e., $g_{\mathrm{syn}} R_{\text {spine }}$ $\gg 1)$, then the spine EPSP begins to approach the synaptic reversal potential $\left(V_{s} \rightarrow E_{\text {syn }}\right)$. The dendritic EPSP then converges to

$$
V_{d} \rightarrow \frac{R_{d} E_{\mathrm{syn}}}{R_{\mathrm{spine}}}=\frac{R_{d} E_{\mathrm{syn}}}{R_{d}+R_{N}} .
$$

In this regime, the synapse acts as a voltage source $\left(\approx E_{\text {syn }}\right)$ and changes in the geometry of the spine neck (changing $R_{N}$ ) can affect the amount of synaptic current entering the spine head. Therefore, the current reaching the dendrite will differ, depending on the length and width of the spine neck. If the dendritic input resistance is too large (i.e., $R_{d} \rightarrow \infty$ ), $V_{d} \rightarrow E_{\mathrm{syn}}$ and varying $R_{N}$ will have no further effect on the dendritic EPSP (see Eq. 7).

In summary, depending on the product of the synaptic conductance change $g_{\text {syn }}$ and the spine input resistance $R_{\text {spine, }}$, the spine-synapse complex tends to act either as a current or as a voltage source. This constrains the extent to which the morphology of the spine can modulate the synaptic efficiency. These relations are illustrated in Figure 5, which shows the simulated effect of spine neck shape on the depolarization at the soma for three different synaptic conductances. For small synaptic conductances (bottom curve), the somatic depolarization is independent of spine shape, but for a large synaptic conductance (top curve) the spine neck can modulate the current over about an order of magnitude.

Technical advances in the last decade have provided tighter bounds on our uncertainty about the spine operating regime. Probably the most complete data are available for the region CA3 pyramidal input (the Schaffer collateral input) to region CA1 pyramidal cells in the hippocampus. This input is mediated by at least two pharmacologically distinct postsynaptic glutamate receptor subtypes: the AMPA subtype, which produces a fast, voltage-independent conductance increase, and the NMDA subtype, which mediates a slower, voltage-dependent conductance increase. Current estimates suggest that at these synapses $g_{\text {AMPA }}$ is about $0.05-0.2 \mathrm{nS}$ (Bekkers and Stevens, 1990; Malinow and Tsien, 1990), while $g_{\mathrm{NMDA}}$ is $<0.5 \mathrm{nS}$ (Bashir et al., 1991).

Based on their EM reconstruction of spines in the same region, Harris and Stevens (1989) estimate the spine neck resistance to lie between about 0.01 and $0.05 \mathrm{G} \Omega$, making the critical product $g_{\text {syn }} R_{\text {spine }}$ much less than 1 for a very large range of dendritic input resistances. Even the assumption that no current can flow through the spine apparatus - thereby effectively restricting the spine neck-will not change this product appreciably, becausc the spine apparatus only occludes about $5-25 \%$ of the spine neck (Harris and Stevens, 1988b). It therefore appears that the synapses of the Schaffer collateral inputs to region CAl spines act as current sources, and that changing spine morphology will not affect the associated dendritic EPSP appreciably (Turner, 1984; Brown et al., 1988; Harris and Stevens, 1989; see also Wilson, 1984). This conclusion is consistent with experimental evidence: while the mechanisms underlying the expression of LTP at these synapses remain controversial (Brown et al., 1988a; Madison et al., 1991), there is little to suggest that a postsynaptic change in the electrical impedance of the spine is involved (see also Larson and Lynch, 1991). This conclusion is also likely to hold in neocortex, unless synaptic conductance

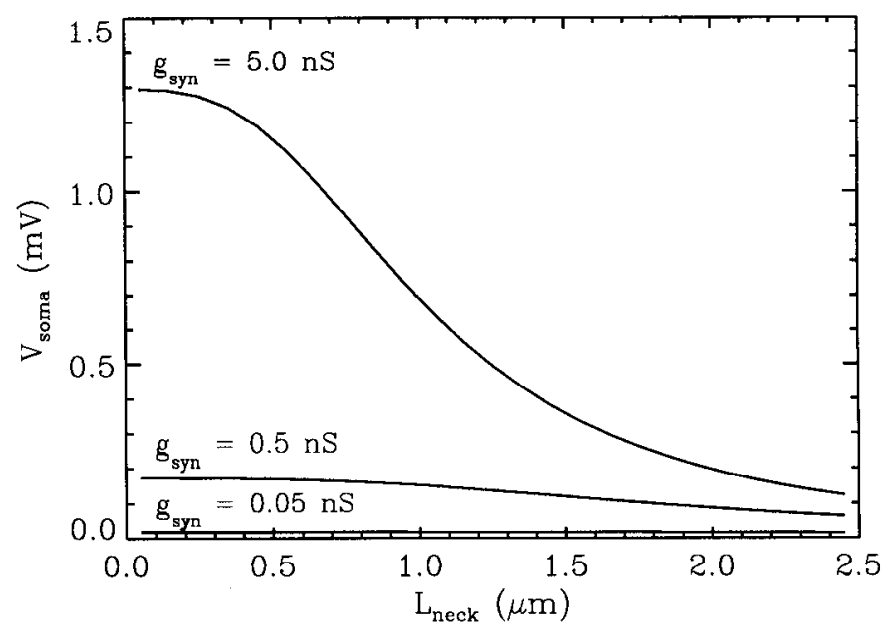

Figure 5. Peak somatic EPSP amplitude as a function of spine neck length $L_{\text {neck }}$ for three different values of the transient, voltage-independent, synaptic input conductance $g_{\text {syn }}$ on the spine head $\left(t_{\text {peak }}=1.5 \mathrm{msec}\right)$ in a simulated pyramidal cell. The geometry was varied to keep the spine neck area constant at $0.24 \mu \mathrm{m}^{2}$, while the $L_{\text {neck }}$ was stretched or compressed (making the spine neck resistance $R_{N}$ proportional to $L_{\text {neck }}^{3}$. For small values of $g_{\text {syn }}$, the synaptic input can be approximated as a current and the spine geometry has little effect on the dendritic or somatic EPSP amplitude. Values for both the AMPA as well as the NMDA component of the CA3 synaptic input onto CA1 cells are believed to be $<0.5 \mathrm{nS}$. The spine in this simulation was located on the proximal portion of the apical tree of an HRP-filled and anatomically reconstructed layer $\mathrm{V}$ pyramidal cell in area 17 of the anesthetized cat (Douglas et al., 1991; for more details, see Bernander et al., 1991).

changes are substantially larger and spines thinner and longer than in hippocampus.

\section{Regenerative electrical properties of spines}

Computer simulations show that if the membrane of the spine head is endowed with regenerative, voltage-dependent fast sodium or calcium channels, even small synaptic inputs can trigger electrical spikes in the spine head, giving rise to sizeable EPSPs in the passive dendrite (Perkel and Perkel, 1985; Shepherd et al., 1985; Segev and Rall, 1988; Baer and Rinzel, 1991). Such spikes do not occur if the neck is too short or too thick, since the associated spine input resistance will then be too small to cause the EPSP to depolarize above spike threshold levels. In principle, small changes in the spine geometry can have a dramatic effect upon $V_{d}$ by enabling or disabling spine action potentials. Given the high degree of voltage attenuation to which high-frequency electrical events - such as slow or fast dendritic spikes-are subject as they propagate from dendrites to the cell body (Rinzcl and Rall, 1974; Mcl, 1992), clcctrical spikes occurring in more distal spines would be difficult to record at the cell body.

Little is known about the presence of voltage-dependent channels in dendritic spines in cortical or hippocampal cells. However, direct immunocytochemical evidence for fast voltage-dependent calcium channels in spines of cerebellar Purkinje cells has recently been provided (Hillman et al., 1991; see also Jones et al., 1989). It may well be that regenerative electrical properties are important to spine function in some cases.

\section{Third Hypothesis: Spines Play a Biochemical Role}

Over the last decade, an alternative view of spines has emerged that emphasizes their effect on chemical rather than electrical 


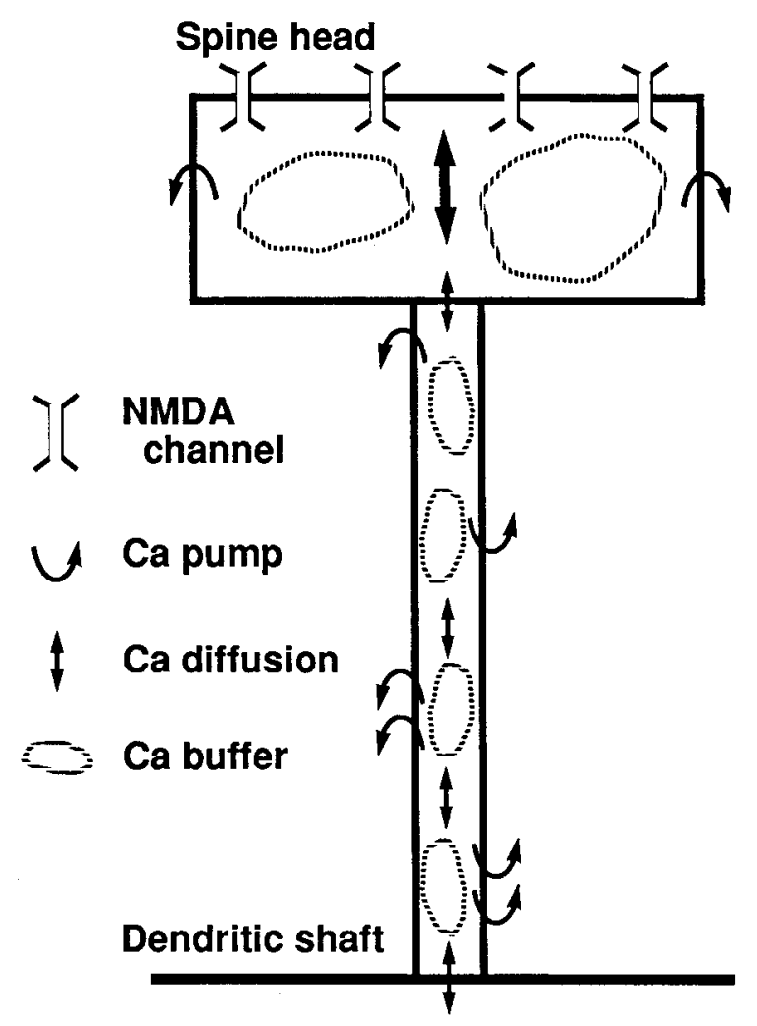

Figure 6. Schematic of the system controlling intracellular calcium in a dendritic spine. The electrical model is similar to Figure 4, except that the synaptic conductance $g_{\mathrm{syn}}(t)$ has been replaced by a voltagedependent NMDA conductance and a voltage-independent AMPA conductance in parallel (not shown). $\mathrm{Ca}^{2+}$ ions enter through the NMDA receptor channels, are bound to the four calcium-binding sites on the calmodulin molecules, diffuse down the neck to the dendrite or can be removed by two different calcium pumps (for more details, see Zador et al., 1990).

signaling. Chemical dynamics may be particularly important in the induction of LTP. The induction of LTP at the Schaffer collateral input to region CAl pyramidal neurons requires an increase in the concentration of intracellular calcium, $\left[\mathrm{Ca}^{2+}\right]_{i}$, at the postsynaptic site; this increase is thought to be mediated by $\mathrm{Ca}^{2+}$ influx through the NMDA receptor complex (Dunwiddie and Lynch, 1979; Collingridge et al., 1983; Lynch et al., 1983; Harris et al., 1984; Malenka et al., 1988; reviewed in Brown et al., 1988a).

From a computational point of view, NMDA synapses on spines can serve to implement a Hebbian rule (Stent, 1973; Brown et al., 1988a). Accordingly, computer models have increasingly focused on the role of spines in modulating calcium dynamics following synaptic input (Robinson and Koch, 1984; Coss and Perkel, 1985; Pongracz, 1985; Gamble and Koch, 1987; Holmes and Levy, 1990; Zador et al., 1990; Brown et al., 1991; Koch et al., 1992).

Because the cable equation governing electrical signal propagation is analogous to the reaction-diffusion equation governing passive diffusion and buffering of $\mathrm{Ca}^{2+}$ ions, insights obtained from the analysis of membrane potential can be applied to the analysis of calcium dynamics. In many respects the results are similar, but in others the conclusions are quite different, owing to differences in the relevant biophysical parameters.

The ability of spines to amplify signals, whether chemical or electrical, can be understood by defining-by analogy with the conventional electrical input resistance-a "chemical input re- sistance" (T. Zador and C. Koch, unpublished observations; see also Carnevale and Rosenthal, 1992), as the change in calcium concentration in response to a current of calcium ions. Both the electrical as well as the calcium spine input resistances will be much larger than the associated dendritic input resistances. As a consequence, a given current flowing into the spine gives rise to a much larger local response than the same current flowing into the dendrite.

A key difference between the electrical and chemical effects of spines arises from the effect of the spine neck. In our analysis of the passive electrical properties of spines above, we concluded that the electrical current loss through the spine neck was negligible. To compare the loss of calcium current through the spine neck membrane, one can define the equivalent of the space constant, which describes the distance over which $\left[\mathrm{Ca}^{2+}\right]$ at steady state decreases $e$-fold in an infinite cable. This definition requires certain simplifying assumptions about the spine $\mathrm{Ca}^{2+}$ dynamics, namely, the presence of linear nonsaturable pumps in the neck, a constant extracellular $\left[\mathrm{Ca}^{2+}\right]$, and a simple calcium buffer scheme. Assuming that a $0.1-\mu \mathrm{m}$-thin spine neck has the parameters used in Zador et al. (1990), the "diffusive space constant" $\lambda_{\mathrm{Ca}}$ is $\approx 0.3 \mu \mathrm{m}$ (Zador and Koch, unpublished observations), about three orders of magnitude smaller than the steady-state electrical space constant. From this we can estimate the calcium concentration at the dendritic shaft in response to a steady-state current inflow at the spine head. Since for these parameters the dendritic shaft is about three space-constants away from the spine head, the calcium concentration at the shaft is expected to be at least $e^{3} \approx 20$-fold lower than at the head. This is in dramatic contrast to the almost complete lack of electrical current attenuation experienced between the spine head and the base.

These principles are illustrated in computer simulations of the fully nonlinear calcium dynamics thought to underlie the induction of LTP (Fig. 7; for details, see Zador et al., 1990; Brown et al., 1991). In the model, calcium enters through NMDA receptor-gated channels on a spine head and diffuses along the spine neck into the dendritc. The model also includes two saturable pumps and the nonlinear calcium buffer protein, calmodulin. Simulated calcium dynamics following a train of synaptic stimuli are shown in Figure 7. Due to the small volume of the spine, the small $\mathrm{Ca}^{2+}$ influx following synaptic stimulation leads to a large transient increase in the spine calcium concentration (for the region CAl spine used in these simulations, $\left[\mathrm{Ca}^{2+}\right]_{s}=10 \mu \mathrm{M}$ corresponded to only about $300 \mathrm{Ca}^{2+}$ ions). Thus, spines can dramatically amplify the small incoming calcium signal. However, due to the mismatch in volumes, the increase in the dendritic $\left[\mathrm{Ca}^{2+}\right]_{i}$ is very small (several tens of nanomoles per liter).

Figure 8 illustrates both voltage and calcium attenuation along the spine neck, that is, the ratio of voltage (or calcium concentration) at one location to the voltage (or calcium concentration) at another location, for two different manipulations. In one case, the relative peak calcium increase due to influx through the NMDA receptor channel is illustrated from the spine head to the dendrite, as is the associated peak voltage attenuation. In a separate simulation, the concentration of calcium in the dendrite, $\left[\mathrm{Ca}^{2+}\right]_{d}$, was "clamped" to $1 \mu \mathrm{M}$. The spine head, however, remained protected from these high calcium values by the presence of calcium pumps in the membrane of the spine neck (Zador et al., 1990), providing a graphic illustration of the tiny size of the associated space constant. Because the corresponding electrical leak conductance across the neck is negligible, almost 


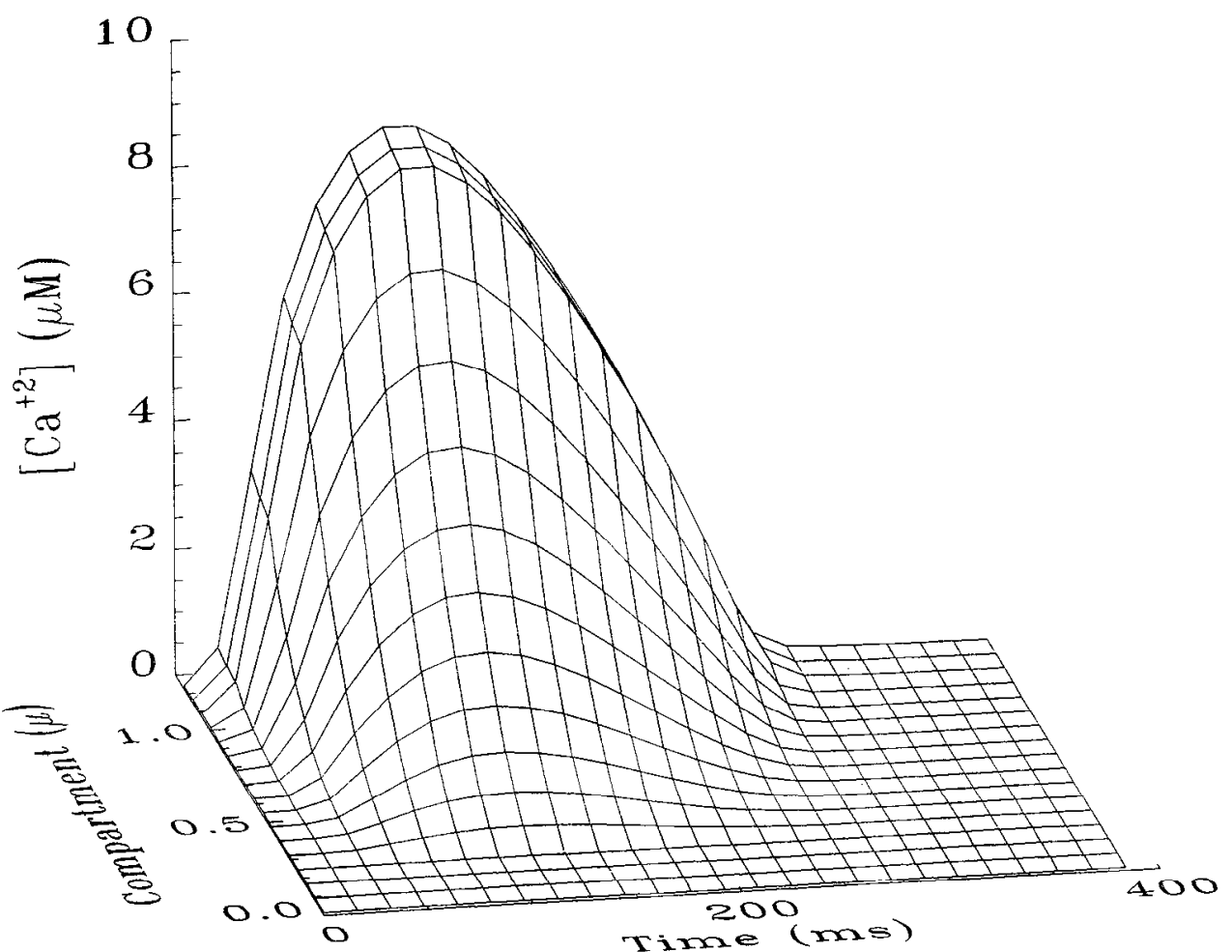

Figure 7. Spatiotemporal dynamics of $\mathrm{Ca}^{2+}$ in response to a train of three presynaptic stimuli (at $100 \mathrm{~Hz}$ ) while the membrane potential in the spine was simultaneously clamped to $-40 \mathrm{mV}$. Changes in $\left[\mathrm{Ca}^{2+}\right]_{i}$-induced by the calcium influx through the NMDA receptor channel-are restricted mainly to the spine head. The axis labeled compartment indicates distance from the dendritic shaft (at the origin; the spine neck ends at $1.0 \mu \mathrm{m}$ and the NMDA synapse is located just below the membrane at the spine head at $1.3 \mu \mathrm{m})$ (from Zador et al., 1990) no electrical attenuation occurs when the dendrite is clamped to a fixed potential. In other words, spines may be electrical accessible but chemically isolated.

It remains technically impossible to record spine EPSPs directly, so hypotheses about spine electrical function must be evaluated indirectly. Experimental techniques for assessing the more recent theoretical results on the biochemical effects of spines have developed much more rapidly. Chief among these techniques has been the optical measurement of calcium concentration by calcium-sensitive dycs. Two recent reports have used the calcium-dependent changes in the fluorescence of intracellular fura-2 in hippocampal neurons to test these hypotheses.

Müller and Connor (1991) studied the isolation of the dendrite from chemical changes at presumed spine heads under conditions of orthodromic stimulation. Using a protocol of strong electrical stimulation to the associative/commissural distal input to region CA3 neurons, they found an increase in intraspine calcium concentration ( $\left[\mathrm{Ca}^{2+}\right]_{s}$ ) from a resting level of about 50 $\mathrm{nM}$ to levels in excess of $1 \mu \mathrm{M}(1.3 \pm 0.5 \mu \mathrm{M})$; in contrast, the increase at the parent dendrite was much less (to $370 \pm 120$ $\mathrm{nM})$. Since the image was acquired over $200 \mathrm{msec}$, the actual peak $\left[\mathrm{Ca}^{2+}\right]_{s}$ may have been underestimated, and because of laterally projecting spines the actual increase at the dendrite may have been overestimated. The increase was blocked by the NMDA receptor antagonist D-2-amino-5-phosphonovalerate (AP5) suggesting that entry was directly through NMDA receptor-gated channels, possibly localized on the spine head.

Guthrie et al. (1991) employed a similar technique to assess the isolation of presumed spine heads from $\left[\mathrm{Ca}^{2+}\right]$ changes at the dendrite under conditions of antidromic stimulation in CA 1 pyramidal cells. Using controllable photoinduced damage to increase the intradendritic calcium concentration $\left(\left[\mathrm{Ca}^{2+}\right]_{d}\right)$ to

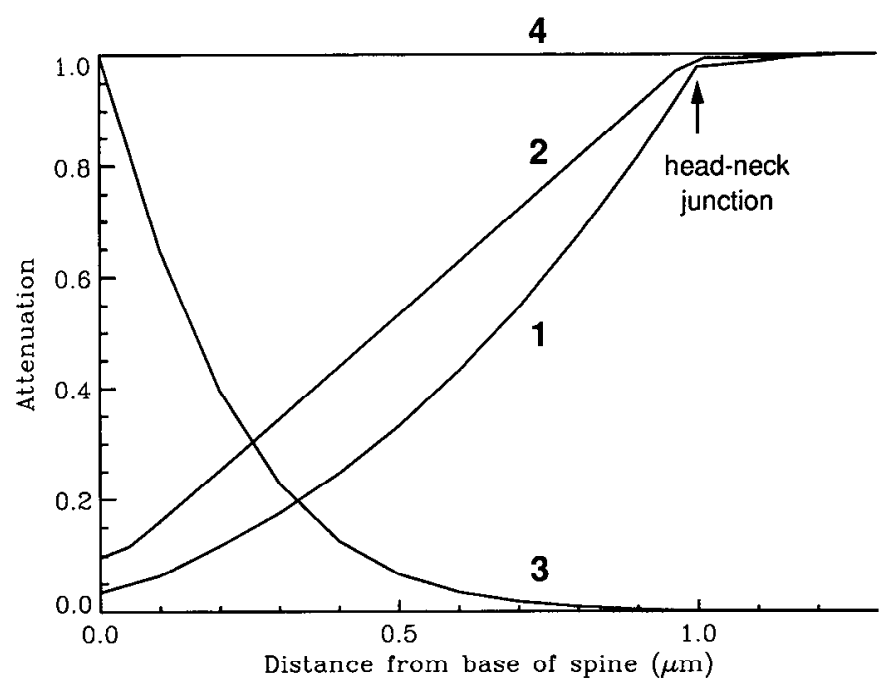

Figure 8. Voltage and calcium attenuation under two different conditions as a function of distance, from the base of the dendrite (at the origin) to the head of the spine just below the NMDA channels (at 1.3 $\mu \mathrm{m}$; the spine neck ends at $1.0 \mu \mathrm{m}$; see arrow). Curve 1 shows the peak concentration of intracellular free calcium in response to three presynaptic stimuli (taken from Fig. 7). Curve 2 illustrates the associated voliage attenuation. Both voltage and free calcium attenuate by about one order of magnitude from the spine head to the base of the spine. In a different simulation illustrating antidromic steady-state behavior, either the calcium concentration (curve 3) or the membrane potential (curve 4 ) is clamped to a fixed value in the dendrite. Due to the presence of calcium pumps in the spine neck membrane, calcium rapidly attenuates and reaches baseline levels at the spine head, while the dendritic membrane potential has very effective access to the spine head, since practically no electrical attenuation occurs across the spine neck. 
$0.2-1.5 \mu \mathrm{M}$, they found that in a significant minority of spines the increase in $\left[\mathrm{Ca}^{2+}\right]_{s}$ lagged behind the increase in $\left[\mathrm{Ca}^{2+}\right]_{d}$. Control experiments with injected cobalt indicated that the lag was not due to a physical diffusion barrier between the dendrite and the spine, supporting the idea that calcium-dependent processes, such as calcium pumps or other uptake systems, were responsible for isolating the spine head. These calcium-dependent processes might account for how elevated calcium levels in the dendrite in the absence of synaptic stimuli to the spines fail to induce LTP at those spines (Regehr et al., 1989). The work by Müller and Connor (1991) and Guthrie et al. (1991) has given us a first glimpse at calcium changes in spines. Higherresolution methods, such as confocal microscopy imaging of spines (Jaffe and Brown, 1992), are now required to investigate further the dynamics of calcium changes underlying LTP.

\section{Conclusion}

The hypothesis that changes in the electrical resistance of the spine neck can modulate the "weight" of the synapse on the spine has attracted considerable attention since the basic idea was proposed 40 years ago. This hypothesis appears not to be valid for the particular case where it has been most carefully evaluated - the Schaffer collateral input to region CAl pyramidal cell. Here the spine neck conductance appears to be too large relative to the synaptic conductance change to provide effective modulation of the amplitude of the synaptic current generated at the spine head.

Both theoretical and experimental support is now accumulating for the alternative hypothesis that spines create an isolated biochemical microenvironment around synapses. In the induction of Hebbian LTP, for example, spincs could restrict changes in postsynaptic calcium concentration to precisely those synapses that meet the criteria for potentiation. Furthermore, changes in spine shape could control the peak calcium concentration induced by synaptic input: all other factors being equal, long and skinny spines would have higher peak levels than short and stubby spines. This could provide an alternative explanation for some of the environmental effects on spine morphology. The biochemical compartmentalization provided by dendritic spines could, of course, also be important for a number of other second messengers, such as inositol trisphosphate, cGMP, and so on, that can diffuse within the intracellular cytoplasm. Thus, spines appear to be unlikely to play an important electrical role in the expression of synaptic plasticity but may play a crucial chemical role by providing a protected microenvironment for calcium and other second messengers.

\section{References}

Amaral DG, Ishizuka N, Claiborne BJ (1990) Neurons, numbers and the hippocampal network. Prog Brain Res 83:1-11.

Anderson JC, Douglas RJ, Martin KAC, Nclson JC, Whitteridge D (in press) Evidence for a significant excitatory input to the dendritic shafts of spiny stellate cells in cat visual cortex. J Physiol (Lond), in press.

Baer SM, Rinzel J (1991) Propagation of dendritic spikes mediated by excitable spines: a continuum theory. J Neurophysiol 65:874-890.

Bashir ZI, Alford S, Davies SN, Randall AD, Collingridge GL (1991) Long-term potentiation of NMDA receptor-mediated synaptic transmission in the hippocampus. Nature 349:156-158.

Bekkers JM, Stevens CF (1990) Presynaptic mechanism for long-term potentiation in the hippocampus. Nature 346:724-729.

Bernander Ö, Douglas RJ, Martin KAC, Koch C. (1991) Synaptic background activity influences spatiotemporal integration in single pyramidal cells. Proc Natl Acad Sci USA 88:11569-11573.
Bliss TVP, Lomo T (1973) Long-lasting potentiation of synaptic transmission in the dentate area of the anaesthetized rabbit following stimulation of the perforant path. J Physiol (Lond) 232:331-356.

Bradley P, Horn G (1979) Neuronal plasticity in the chick brain: morphological effects of visual experience on neurons in hyperstriatum accessorium. Brain Res 162:1481-153.

Braitenberg V, Atwood RP (1958) Morphological observations in the cerebellar cortex. J Comp Neurol 109:1-34.

Brandon JG, Coss RG (1982) Rapid dendritic spine stem shortening during one-trial learning: the honeybee's first orientation flight. Brain Res 252:51-61.

Brown TH, Chapman PF, Kairiss EW, Keenan CL (1988a) Long-term potentiation. Science 242:724-728.

Brown TH, Chang VC, Ganong AH, Keenan CL, Kelso SR (1988b) Biophysical properties of dendrites and spines that may control the induction and expression of long-term synaptic potentiation. In: Long term potentiation: from biophysics to behavior (Landfield PW, Deadwyler SA, eds), pp 201-264. New York: Liss.

Brown TH, Zador AM, Mainen ZF, Claiborne JB (1991) Hebbian modifications in hippocampal neurons. In: Long term potentiation: a debatc of current issucs (Davis J, Baudry M, cds), pp 357-389. Cambridge, MA: MIT Press.

Brown TH, Zador AM, Mainen ZF, Claiborne JB (1992) Hebbian computations in hippocampal dendrites and spines. In: Single neuron computation (McKenna T, Davis J, Zornetzer SF, eds), pp 81-116. Boston: Academic.

Burgoyne RD, Gray EG, Barron J (1983) Cytochemical localization of calcium in the dendritic spine apparatus of the cerebral cortex and at synaptic sites in the cerebellar cortex. J Anat 136:634-635.

Caceres A, Bender P, Snavely L, Rebhun LL, Steward O (1983) Distribution and subcellular localization of calmodulin in adult and developing brain tissue. Neuroscience 10:394-410.

Carlin RK, Bartlet DC, Siekevitz P (1983) Identification of fodrin as a major calmodulin-binding protein in postsynaptic density preparation. J Ccll Biol 96:443-448.

Carnevale NT, Rosenthal S (1992) Kinetics of diffusion in a spherical cell. I. No solute buffering. J Neurosci Methods 41:205-216.

Chang HT (1952) Cortical neurons with particular reference to the apical dendrites. Cold Spring Harbor Symp Quant Biol 17:189-202.

Claiborne JB, Zador AM, Mainen ZF, Brown TH (1992) Computational models of hippocampal neurons. In: Single neuron computation (McKenna T, Davis J, Zornetzer SF, eds), pp 62-80. Boston: Academic.

Collingridge GL, Kehl SJ, McLennan H (1983) Excitatory amino acids in synaptic transmission in the Schaffer collateral-commissural pathway of the rat hippocampus. J Physiol (Lond) 334:33-46.

Coss RG, Globus A (1978) Spine stems on tectal interneurons in jewel fish are shortened by social stimulation. Science 200:787-789.

Coss RG, Pcrkel DH (1985) The function of dendritic spines-a review of theoretical issues. Behav Neural Biol 44:151-185.

Crick F (1982) Do dendritic spines twitch? Trends Neurosci 5:44-46.

Dehay C, Douglas RJ, Martin KAC, Nelson C (1991) Excitation by geniculo-cortical synapses is not 'vetoed' at the level of dendritic spines in cat visual cortex. J Physiol (Lond) 440:723-734.

Desmond NL, Levy WB (1988) Anatomy of associative long-term synaptic modification. In: Long term potentiation: from biophysics to behavior (Landfield PW, Deadwyler SA, eds), pp 265-305. New York: Liss.

Diamond J, Gray EG, Yasargil GM (1970) The function of the dendritic spine. In: Excitatory synaptic mechanisms (Andersen P, Jansen J, eds), pp 212-222. Oslo: Universitetsforlag.

Douglas RJ, Martin KAC (1990) Neocortex. In: The synaptic organization of the brain (Shepherd GM, cd), pp 220-243. London: Oxford UP.

Douglas RJ, Martin KAC, Whitteridge D (1991) An intracellular analysis of the visual responses of neurones in cat visual cortex. J Physiol (Lond) 440:659-698.

Drenckhahn D, Kaiser HW (1983) Evidence for the concentration of F-actin and myosin in synapses and in the plasmalemmal zone of axons. Eur J Cell Biol 31:235-240.

Dunwiddie TV, Lynch G (1979) The relationship between extracellular calcium concentrations and the induction of long-term potentiation. Brain Res 169:103-110.

Fifkova E (1985) A possible mechanism of morphometric changes in dendritic spines induced by stimulation. Cell Mol Neurobiol 5:4763. 
Fifkova E, Delay RJ (1982) Cytoplasmic actin in neuronal processes as a possible mediator of synaptic plasticity. J Cell Biol 95:345-350.

Fifkova E, Anderson CL, Young SJ, Van Harrefeld A (1982) Effect of anisomycin on stimulation-induced changes in dendritic spines of the dentate granule cells. J Neurocytol 11:183-210.

Fifkova E, Markham JA, Delay RJ (1983) Calcium in the spine apparatus of dendritic spines in the dendate molecular layer. Brain Res 266:163-168.

Gamble E, Koch C (1987) The dynamics of free calcium in dendritic spines in response to repetitive synaptic input. Science 236:13111315.

Gray EG (1959) Axo-somatic and axo-dendritic synapses of the cerebral cortex: an electron-microscopic study. J Anat 93:420-433.

Greenough WT, Chang F-LF (1985) Synaptic structural correlates of information storage in the mammalian nervous system. In: Synaptic plasticity (Cotman CW, ed), pp 335-372. New York: Guilford.

Guthrie PB, Segal M, Kater SB (1991) Independent regulation of calcium revealed by imaging dendritic spincs. Nature 354:76-80.

Harris EW, Ganong AH, Cotman CW (1984) Long-term potentiation in the hippocampus involves activation of $N$-methyl-D-aspartate receptors. Brain Res 323:132-137.

Harris KM, Stevens JK (1988a) Study of dendritic spines by serial electron microscopy and three-dimensional reconstruction. In: Intrinsic determinants of neuronal form and function (Lasek RJ, Black MM, eds), pp 179-199. New York: Liss.

Harris KM, Stevens JK (1988b) Dendritic spines of rat cerebellar Purkinje cells: serial electron microscopy with reference to their biophysical characteristics. J Neurosci 8:4455-4469.

Harris KM, Stevens JK (1989) Dendritic spines of CAl pyramidal cells in the rat hippocampus: serial electron microscopy with reference to their biophysical characteristics. J Neurosci 9:2982-2997.

Harris KM, Jensen FE, Tsao BH (1989) Ultrastructure, development and plasticity of dendritic spine synapses in area CAl of the rat hippocampus: extending our vision with serial electron microscopy and three-dimensional analyses. In: The hippocampus-new vistas (Chan-Palay V, Kohler C, eds), pp 33-52. New York: Liss.

Harris KM, Jensen FE, Tsao BH (1992) Three-dimensional structure of dendritic spines and synapses in rat hippocampus (CA1) at postnatal day 15 and adult ages: implications for the maturation of synaptic physiology and long-term potentiation. J Neurosci 12:26852705.

Hillman D, Chen S, Aung TT, Cherksey B, Sugimore M, Llinas RR (1991) Localization of P-type calcium channels in the central nervous system. Proc Natl Acad Sci USA 88:7076-7080.

Holmes WR (1989) The role of dendritic diameter in maximizing the effectiveness of synaptic inputs. Brain Res 478:127-137.

Holmes WR, Levy WB (1990) Insights into associative long-term potentiation from computational models of NMDA receptor-mediated calcium influx and intracellular calcium concentration changes. J Neurophysiol 63:1148-1168.

Jack JJB, Noble D, Tsien RW (1975) Electric current flow in excitable cells. London: Oxford UP.

Jaffe DB, Brown TH (1992) Confocal imaging of thorny excrescences on hippocampal pyramidal neurons. Soc Neurosci Abstr 18:564.3.

Jaslove SW (1992) The integrative properties of spiny distal dendrites. Neuroscience 47:495-519.

Jones EG, Powell TPS (1969) Morphological variations in the dendritic spines of the neocortex. J Cell Sci 5:509-529.

Jones OT, Kunze DL, Angelides KJ (1989) Localization and mobility of omega-conotoxin-sensitive $\mathrm{Ca}^{2+}$ channels in hippocampal CA1 neurons. Science 244:1189-1193.

Koch C, Poggio T (1983a) A theoretical analysis of electrical properties of spines. Proc R Soc Lond [Biol] 218:455-477.

Koch C, Poggio T (1983b) Electrical properties of dendritic spines. Trends Neurosci 6:80-83.

Koch C, Zador A, Brown TH (1992) Dendritic spines: convergence of theory and experiment. Science 256:973-974.

Larkman AU (1991) Dendritic morphology of pyramidal neurons of the visual cortex of the rat: III. Spine distribution. J Comp Neurol 306:332-343.

Larson J, Lynch G (1991) A test of the spine resistance hypothesis for LTP expression. Brain Res 538:347-350.

Lee KS, Schottler F, Oliver M, Lynch G (1980) Brief bursts of highfrequency stimulation produce two types of structural changes in the rat hippocampus. J Neurophysiol 44:247-258.
I eVay S (1986) Synaptic organization of claustral and geniculate afferents to the visual cortex of the cat. J Neurosci 6:3564-3575.

Lynch G, Larsen J, Kelso S, Barrionuevo G, Schottler F (1983) Intracellular injections of EGTA block induction of hippocampal LTP. Nature 305:719-721.

Madison DV, Malenka RC, Nicoll RA (1991) Mechanisms underlying long-term potentiation of synaptic transmission. Annu Rev Neurosci 14:379-398.

Malenka RC, Kauer JA, Zucker RS, Nicoll RA (1988) Postsynaptic calcium is sufficient for potentiation of hippocampal synaptic transmission. Science 242:81-84.

Malinow R, Tsien RW (1990) Presynaptic enhancement shown by whole-cell recordings of long-term potentiation in hippocampal slices. Nature 346:177-180.

Martin KAC (1988) From single cells to simple circuits in the cerebral cortex. Q J Exp Physiol 73:637-702.

Martin KAC, Whitteridge D (1984) Form, function and intracortical projections of spiny neurons in the striate visual cortex of the cat. J Physiol (Lond) 353:463-504.

Mel BW (1992) NMDA-based pattern discrimination in a modeled cortical neuron. Neural Comput 4:502-516.

Müller W, Connor JA (1991) Dendritic spines as individual neuronal compartments for synaptic $\mathrm{Ca}^{2+}$ responses. Nature 354:73-76.

Perkel DH, Perkel DJ (1985) Dendritic spines: role of active membrane in modulating synaptic efficiency. Brain Res 325:331-335.

Peters A, Kaiserman-Abramof IR (1970) The small pyramidal neuron of the rat cerebral cortex. The perikaryon, dendrites and spines. Am J Anat 127:321-356.

Pongracz. F (1985) The function of dendritic spines: a theoretical study. Neuroscience 15:933-946.

Purpura D (1974) Dendritic spines "dysgenesis" and mental retardation. Science 186:1126-1128.

Qian N, Sejnowski TJ (1989) An electro-diffusion model for computing membrane potentials and ionic concentrations in branching dendrites, spines and axons. Biol Cybern 62:1-15.

Qian N, Sejnowski TJ (1990) When is an inhibitory synapse effective. Proc Natl Acad Sci USA 87:8145-8149.

Rall, W (1970) Cable properties of dendrites and effects of synaptic location. In: Excitatory synaptic mechanisms (Anderson P, Jansen JKS, eds), pp 175-187. Oslo: Universitetsforlaget.

Rall W (1974) Dendritic spines, synaptic potency and neuronal plasticity. In: Cellular mechanisms subserving changes in neuronal activity (Woody CD et al., eds), pp 13-21. Los Angeles: University of California.

Rall W. (1978) Dendritic spines and synaptic potency. In: Studies in neurophysiology (Porter R ed), pp 203-209. Cambridge: Cambridge UP.

Rall W, Rinzel J (1971) Dendritic spine function and synaptic attenuation. Soc Neurosci Abstr 1:64.

Rall W, Shepherd GM (1968) Theoretical reconstruction of field potentials and dendro-dendritic synaptic interactions in olfactory bulb. J Neurophysiol 31:884-915.

Ramon y Cajal S (1991) New ideas on the structure of the nervous system of man and vertebrates. From: Les nouvelles idees sur la structure du systeme nerveux chez l'homme et chez les vertebres (Swanson N, Swanson LM, transl). Cambridge, MA: MIT Press.

Rausch G, Scheich H (1982) Dendritic spine loss and enlargement during maturation of the speech control system in the mynah bird (Gracula religiosa). Neurosci Lett 29:129-133.

Regehr WG, Connor J A, Tank DW (1989) Optical imaging of calcium accumulation in hippocampal pyramidal cells during synaptic activation. Nature 341:533-536.

Rinzel J (1982) Neuronal plasticity (learning). In: Lectures on mathematics in the life sciences (Miura RM, ed), pp 7-25. Providence, RI: American Mathematical Society.

Rinzel J, Rall W (1974) Transient response in a dendritic neuron model for current injection at one branch. Biophys J 14:759-790.

Robinson HPC, Koch C (1984) Artificial intelligence Memo 779, Calcium, spines and memory: a specific proposal. Cambridge, MA: MIT Artificial Intelligence Laboratory.

Schüz A (1976) Pyramidal cells with different densities of dendritic spines in the cortex of the mouse. Z Naturforsch 31c:319-323.

Segev I, Rall W (1988) Computational study of an excitable dendritic spine. J Neurophysiol 60:499-523.

Segev I, Rapp M, Manor Y, Yarom Y (1992) Analog and digital processing in single nerve cells: dendritic integration and axonal prop- 
agation. In: Single neuron computation (McKenna T, Davis J, Zornetzer SF, eds), pp 173-198. Boston: Academic.

Shepherd GM, Greer CA (1989) The dendritic spine: adaptations of structure and function for different types of synaptic integrations. In: Intrinsic determinants of neuronal form and function (Lasek R, Black $M$, eds), pp 245-314. New York: Liss.

Shcpherd GM, Brayton RK, Miller JF, Segev I, Rinzel J, Rall W (1985) Signal enhancement in distal cortical dendrites by means of interactions between active dendritic spines. Proc Natl Acad Sci USA 82: 2192-2195.

Stent GS (1973) A physiological mechanism for Hebb's postulate of learning. Proc Natl Acad Sci USA 70:997-1001.

Stratford AU, Mason A, Larkman AU, Major G, Jack JJB (1989) The modelling of pyramidal neurons in the visual cortex. In: The computing neuron (Durbin R, Miall C, Mitchison G, eds), pp 296-321. Workingham, UK: Addison-Wesley.

Swindale NV (1981) Dendritic spines only connect. Trends Neurosci $4: 240-241$.
Turner DA (1984) Conductance transients onto dendritic spines in a segmental cable model of hippocampal neurons. Biophys J 46:85-96.

Van Harrefeld A, Fifkova E (1975) Swelling of dendritic spines in the fascia dentata after stimulation of the perforant fibers as a mechanism of post-tetanic potentiation. Exp Neurol 49:736-749.

White EL, Rock MP (1980) Three-dimensional aspects and synaptic relationships of a Golgi-impregnated spiny stellate cell reconstructed from serial thin sections. J Neurocytol 9:615-636.

Wilson CJ (1984) Passive cable properties of dendritic spines and spiny neurons. J Neurosci 4:281-297.

Wilson CJ, Groves PM, Kitai ST, Linder JC (1983) Three-dimensional structure of dendritic spines in the rat neostriatum. J Neurosci 3:383398.

Woolley CS, Gould E, Frankfurt M, McEwen BS (1990) Naturally occurring fluctuations in dendritic spine density on adult hippocampal pyramidal neurons. J Neurosci 10:4035-4039.

Zador T, Koch C, Brown T (1990) Biophysical model of a Hebbian synapse. Proc Natl Acad Sci USA 87:6718-6722. 